\title{
Phylogenetic analysis based on mitochondrial COI gene sequences in Thrips tabaci Lindeman (Thysanoptera: Thripidae) in relation to reproductive forms and geographic distribution
}

\author{
Satoshi Toda ${ }^{1, *}$ and Tamotsu MUraI ${ }^{2}$ \\ ${ }^{1}$ Grape and Persimmon Research Station, National Institute of Fruit Tree Science; Higashihiroshima, Hiroshima 739-2494, Japan \\ ${ }^{2}$ Department of Bioproductive Science, Utsunomiya University; Utsunomiya 321-8505, Japan
}

(Received 26 June 2006; Accepted 28 December 2006)

\begin{abstract}
Thrips tabaci Lindeman is an extensively distributed pest insect that injures a wide range of crops. To investigate the intra-specific genetic diversity of this species, we analyzed an $810 \mathrm{bp}$ region of the mitochondrial cytochrome oxidase gene subunit I (COI). Eight populations from six foreign countries and 18 Japanese populations were tested, and 17 different haplotypes were identified. Apparent differences were found between arrhenotokous and thelytokous strains in their COI sequences. A phylogenetic tree of the COI gene shows two distinct groups. We assume that these two groups correspond respectively to the arrhenotokous strain and the thelytokous strain. Japanese thelytokous types consisted of five haplotypes. Two haplotypes were identified from problematic populations in terms of the greater amount of damage they caused and the development of insecticide resistance. Both haplotypes were also found overseas, suggesting that some strains from overseas may have caused the above-mentioned problems in Japan.
\end{abstract}

Key words: Thrips tabaci; reproductive forms; phylogenetic analysis; COI; haplotype

\section{INTRODUCTION}

The onion thrips, Thrips tabaci Lindeman, is a major pest of alliaceous crops and is distributed widely throughout the world. This thrips has been known as a vector of tomato spotted wilt virus (TSWV) (Zawirska, 1976) and was recently recognized as a transmitter of a new tospovirus, Iris yellow spot virus (IYSV) (Doi et al., 2003). Although T. tabaci is a highly polyphagous species, it has been noted that there are several strains with different host preferences (Zawirska, 1976). Using RAPD-PCR analysis, Jenser et al. (2001) revealed a genetic difference between two populations collected from tobacco and onion, respectively. More recently, Brunner et al. (2004) conducted molecular phylogenetic analysis based on sequences of the mitochondrial cytochrome oxidase subunit I (COI) gene in some European populations and suggested that $T$. tabaci must be a complex of cryptic (sub) species in association with host preference.
Moreover, it is known that $T$. tabaci has two different reproductive forms, arrhenotoky and thelytoky, and shows geographic variation in the sex ratio (reviewed in Jenser and Szénási, 2004). Arrhenotoky is a form of parthenogenesis in which unfertilized eggs develop into haploid males, while thelytoky is complete parthenogenetic reproduction. Murai (1990) found that these two reproductive types are distinguishable by esterase zymogram. Nakao and Yabu (1998) suggested that thelytokous and arrhenotokous Thrips nigropilosus correspond to separate species, due to the existence of apparent genetic differences and reproductive isolation; however, the phylogenetic relationship between the two reproductive forms of $T$. tabaci is unclear, and their taxonomical relationship remains obscure.

Recently, T. tabaci has become a more serious pest in Japan. It has begun to cause serious damage to persimmon, which had not been recognized as a host plant of T. tabaci (Morishita and Oue, 2001).

* To whom correspondence should be addressed at: E-mail: toda@affrc.go.jp DOI: $10.1303 / \mathrm{aez} .2007 .309$ 
Moreover, the damage to some crops, Satsuma mandarin (Tsuchiya, 2001; Fujikawa and Muta, 2003), asparagus (Matsumoto, 2004) and ornamental plants (Oida and Mihira, 2001), by T. tabaci has increased. In addition, reduced susceptibility of $T$. tabaci to insecticides has been observed in some areas of Japan (Morishita and Oue, 2001; Oida and Mihira, 2001; Nishimori et al., 2003; Murai, 2004). Recently, insecticide resistance in $T$. tabaci has been reported in the United States (Shelton et al., 2003) and Canada (Allen et al., 2005). These problems prompted us to consider that different strains have invaded Japan.

In this study, we analyzed and compared the nucleotide sequences of the COI gene from two reproductive forms of $T$. tabaci and inferred the degree of their genetic divergence. Furthermore, we conducted phylogenetic analysis to clarify the relationships between the 17 haplotypes found in this study. We then discuss the genetic background of several problems occurring in Japanese T. tabaci populations.

\section{MATERIALS AND METHODS}

Thrips. Japanese T. tabaci samples were collected from a variety of host plants in 18 localities (Table 1). Species were identified by observation of morphological characteristics and a molecular diagnostic method (Toda and Komazaki, 2002). The reproductive form was identified in 13 populations which were offered in a viable condition. When no males appeared for several generations, the population was judged to be thelytokous. Arrhenotokous strains were established by individual rearing of females of populations in which males appeared. Thrips were reared on germinated broad bean (Vicia faba L.) under laboratory conditions $\left(16 \mathrm{~L} 8 \mathrm{D}, 25^{\circ} \mathrm{C}\right)$ according to the method of Murai and Loomans (2001).

Table 1. Collection history and locality of Thrips tabaci

\begin{tabular}{|c|c|c|c|c|c|}
\hline Country & $\begin{array}{l}\text { Population } \\
\text { name }\end{array}$ & Locality & Host plants & Year & Type $^{\mathrm{a}}$ \\
\hline \multirow[t]{18}{*}{ Japan } & $\mathrm{HoNa}$ & Naganuma, Hokkaido Pref. & Allium cepa & 1999 & \\
\hline & AoRo & Rokunohe, Aomori Pref. & Raphanus sativus & 2000 & $\mathrm{TH}$ \\
\hline & IwMo & Morioka, Iwate Pref. & Asteraceae spp. & 1999 & \\
\hline & ChTa & Tateyama, Chiba Pref. & Eustoma grandiflorum & 2003 & \\
\hline & $\mathrm{ShHa}$ & Hamamatsu, Shizuoka Pref. & Allium cepa & 1999 & $\mathrm{TH}$ \\
\hline & $\mathrm{NaCh}$ & Chikumagawa, Nagano Pref. & Allium cepa & 2005 & AR \\
\hline & OsHa & Habikino, Osaka Pref. & Allium cepa & 2005 & AR \\
\hline & WaMo & Momoyama, Wakayama Pref. & Diospyros kaki & 2001 & $\mathrm{TH}$ \\
\hline & WaKo & Kokawa, Wakayama Pref. & Allium сера & 2001 & $\mathrm{TH}$ \\
\hline & HiHi-1 & Higashihiroshima, Hiroshima Pref. & Solanum tuberosum & 2001 & $\mathrm{TH}$ \\
\hline & HiHi-2 & Higashihiroshima, Hiroshima Pref. & Allium cepa & 2005 & AR \\
\hline & ShIz & Izumo, Shimane Pref. & Allium cepa & 1989 & AR \\
\hline & $\mathrm{KaKa}$ & Kan-onji, Kagawa Pref. & Asparagus officinalis & 2002 & $\mathrm{TH}$ \\
\hline & $\mathrm{SaKa}$ & Karatsu, Saga Pref. & Allium $\times$ wakegi & 2004 & $\mathrm{TH}$ \\
\hline & $\mathrm{SaGe}$ & Genkai, Saga Pref. & Citrus unshiu & 2004 & $\mathrm{TH}$ \\
\hline & $\mathrm{NaKu}$ & Kuchinotsu, Nagasaki Pref. & Trifolium repens & 2000 & $\mathrm{TH}$ \\
\hline & $\mathrm{KaKu}$ & Kushira, Kagoshima Pref. & Allium fistuiosum & 1999 & \\
\hline & $\mathrm{OkNa}$ & Nago, Okinawa Pref. & Allium sativum & 1998 & \\
\hline Korea & KOR & Suwon & Unknown & 1998 & \\
\hline \multirow[t]{2}{*}{ Netherlands } & NLD-1 & Oudenbosch & Allium porrum & 2000 & M \\
\hline & NLD-2 & Meterik & Allium porrum & 1999 & M \\
\hline France & FRA & Unknown (Imported) & Allium porrum & 2000 & \\
\hline \multirow[t]{2}{*}{ Israel } & ISR-1 & Unknown (Imported) & Dianthus spp. & 2001 & M \\
\hline & ISR-2 & Unknown (Imported) & Liatris spp. & 2000 & M \\
\hline Kenya & KEN & Unknown (Imported) & Dianthus spp. & 2000 & \\
\hline Peru & PER & Unknown (Imported) & Asparagus officinalis & 2001 & \\
\hline
\end{tabular}

${ }^{\mathrm{a}}$ AR: arrhenotoky, TH: thelytoky, M: including males. 
Overseas samples were also used for phylogenetic analysis. Individuals of T. tabaci were collected from six countries: Korea, the Netherlands, France, Israel, Kenya and Peru (Table 1). Samples from the latter four countries were collected from crops imported to the Netherlands. They were offered as specimens in 100\% ethanol.

DNA extraction and PCR amplification. Total genomic DNA was extracted from each single female and male adult thrips after Toda and Komazaki (2002). Thrips were homogenized in $100 \mu 1$ of lysis buffer (100 mM Tris-HCl (pH 8.0), $100 \mathrm{~mm}$ EDTA (pH 8.0), 1\% sodium dodecyl sulfate (SDS), $0.1 \mathrm{mg} / \mathrm{ml}$ proteinase $\mathrm{K}$ ) and incubated for $10 \mathrm{~min}$ at $65^{\circ} \mathrm{C}$. The lysate was extracted once with one volume of TE-saturated phenol and once with chloroform/isoamyl alcohol (24:1). DNA was precipitated with ethanol and resuspended in $10 \mu \mathrm{l}$ of $0.1 \times$ Tris-EDTA (TE) buffer $(1 \mathrm{~mm}$ Tris- $\mathrm{HCl}(\mathrm{pH}$ 8.0), $0.1 \mathrm{~mm}$ EDTA ( $\mathrm{pH} 8.0)$ ) and stored at $-20^{\circ} \mathrm{C}$. To design a specific primer, the cytochrome oxidase subunit I (COI) region of mitochondrial DNA was amplified using the universal primers (sense) 5'-TATAGCATTCCCACGAATAAATAA-3' and (anti-sense) 5'-TACAGCTCCTATAGATAAAAC3', designed by Zhang and Hewitt (1996) and by Navajas et al. (1996), respectively. A specific sense primer, 5'-TATAAGATTCTGACTTTTACCCCC$3^{\prime}$, was designed on the basis of COI sequence data determined using these universal primers. This primer and the above-mentioned universal antisense primer were subsequently used for the analyses. The PCR thermal program in a DNA thermal cycler (DNA thermal cycler 9600, Applied Biosystems) was $95^{\circ} \mathrm{C}$ for $9 \mathrm{~min}$ for pre-heating, and then 35 cycles of $94^{\circ} \mathrm{C}$ for $1 \mathrm{~min}, 50^{\circ} \mathrm{C}$ for $1 \mathrm{~min}$ and $72^{\circ} \mathrm{C}$ for $1 \mathrm{~min}$, and final extension at $72^{\circ} \mathrm{C}$ for 7 min as a final extension. PCR was performed in $40 \mu \mathrm{l}$ reaction volumes, containing $20 \mathrm{pmol}$ of each primer, $10 \mathrm{~mm}$ Tris- $\mathrm{HCl}$ ( $\mathrm{pH} 8.3$ ), $50 \mathrm{mM} \mathrm{KCl}$, $2.5 \mathrm{mM} \mathrm{MgCl}_{2}, 0.25 \mathrm{~mm}$ of each dNTP and 0.5 units of Taq-polymerase (AmpliTaq Gold ${ }^{\circledR}$, Applied Biosystems).

Sequencing. PCR products were purified and dissolved in $0.1 \times$ TE by ultrafiltration using Micro$\operatorname{con}^{\circledR}$ YM-100 (Millipore). They were sequenced directly using the BigDye ${ }^{\circledR}$ Terminator v3.1 Cycle Sequencing Kit (Applied Biosystems) and the ABI Prism ${ }^{\circledR}$ Model 377 automated DNA sequencer. Two specific primers, 5'-GTCTGATCAGTTATTTTA-
ACAGCC-3' and 5'-ATGAGAAATTAGTCCAAATCCTGG-3', were designed on the basis of sequence data determined beforehand and used for sequencing as internal primers. The DNA of each sample was sequenced twice for both strands.

Phylogenetic analysis. Six COI sequence data on T. tabaci submitted by Brunner et al. (2004) were obtained from the DNA database and used for phylogenetic analysis employing the sequence data obtained in this study. As an outgroup, we utilized the complete mitochondrion sequence data of $T$. imaginis (AF335993) (Shao and Barker, 2003). DNA sequences of T. tabaci and T. imaginis were aligned using Clustal W (Thompson et al., 1994). Phylogenetic analysis was performed using the PHYLIP 3.65 (Felsenstein, 2005) package. Divergence between sequences was estimated using the DNADIST program, with Kimura's two parameter distance option (Kimura, 1980). A tree was built using the neighbor-joining method employing the NEIGHBOR program. Bootstrap values were calculated using SEQBOOT and CONSENSE, packaged in PHYLIP. The phylogenetic tree was also estimated using the parsimony (DNAPARS) and maximum likelihood (DNAML) programs packed in PHYLIP.

\section{RESULTS}

The $856 \mathrm{bp}$ region of the mitochondrial COI gene was successfully amplified in 118 specimens. The COI sequences used in this study were $810 \mathrm{bp}$ excluding the primer region. Seventeen different haplotypes were identified. Their sequences have been deposited in the DDBJ nucleotide sequence database under accession numbers AB262428AB262444. Variable nucleotide positions among the 17 COI haplotypes are shown in Table 2. The COI sequences showed polymorphism at 39 nucleotide positions (4.8\%), including 37 transitions and two transversions. Although 38 of these were silent substitutions, one transversion caused an amino acid substitution in Haplotype 4 (Table 2).

Five and two haplotypes were identified from 10 thelytokous and four arrhenotokous populations, respectively (Tables 1 and 3). Table 3 shows the number of nucleotide substitutions in the COI gene among these seven haplotypes. A nucleotide difference between the two arrhenotokous haplotypes (Haplotypes 6 and 7) was found at only one site, 
Table 2. Variable nucleotide positions in the 810 bp region of the 17 COI haplotypes of $T$. tabaci

\begin{tabular}{|c|c|c|c|c|c|c|c|c|c|c|c|c|c|c|c|c|c|c|c|c|c|c|c|c|c|c|c|c|c|c|c|c|c|}
\hline \multirow{2}{*}{ Haplotype } & \multicolumn{33}{|c|}{ Position } \\
\hline & & & & & & & & & & & & & & & & & & & & & & & & & & & & & & 60 & & & \\
\hline 1 & G & A & & A $C$ & & A A & $\mathrm{A} A$ & & A $A$ & $\mathrm{C}$ & $\mathrm{T}$ & $\mathrm{C}$ & $\mathrm{C}$ & A & $A$ & $\mathrm{~T}$ & $\mathrm{C}$ & $\mathrm{C}$ & $\mathrm{T}$ & $\mathrm{GC}$ & $\mathrm{G} \mathrm{A}$ & $\mathrm{AC}$ & $\mathrm{C} \mathrm{C}$ & $\mathrm{C} C$ & $\mathrm{~A}$ & $\mathrm{~T}$ & $\mathrm{C}$ & $\mathrm{C}$ & $\mathrm{T}$ & $\mathrm{A} C$ & & A A & A $T$ \\
\hline 2 & · & $\cdot$ & G & & . & . & $\cdot$ & $\cdot$ & . & . & 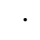 & 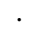 & $\cdot$ & . & 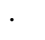 & . & $\cdot$ & $\cdot$ & $\cdot$ & . & $\cdot \cdot$ & $\cdot$ & $\cdot$. & $\cdot \cdot$ & $\cdot$ & 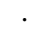 & $\cdot$ & . & $\cdot$ & G $\mathrm{T}$ & $\cdot$. & $\cdot$. & · .. \\
\hline 3 & . & . & . & . & . & . . . & $\mathrm{G}$ & . & 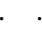 & . & ${ }^{\circ}$ & & . & . & . & $\mathrm{C}$ & $\mathrm{T}$ & $\mathrm{T}$ & . & . & . . . & . & . $\mathrm{T}$ & $\begin{array}{ll}\Gamma \\
\end{array}$ & $\mathrm{G}$ & . & . & . & . & . $\mathrm{T}$ & . . & . . & - $\mathrm{C}$ \\
\hline 4 & A & & . & 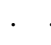 & . & . . & G & . & .. & $\mathbf{T}$ & . & . & . & G & 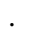 & . & T & $\mathrm{T}$ & $\cdot$ & . . & .. & . & . $\mathrm{T}$ & $\Gamma \mathrm{T}$ & $\mathrm{G}$ & . & $\cdot$ & . & . & $\cdot \mathrm{T}$ & . . & . . & .. \\
\hline 5 & - & . & . & . & . & .. & G & . & . & . & $\cdot$ & . & . & $\mathrm{G}$ & . & . & $\mathrm{T}$ & $\mathrm{T}$ & . &.$\quad$. & . $\cdot$ & . & . $\mathrm{T}$ & $\Gamma \mathrm{T}$ & $\mathrm{G}$ & . & $\mathrm{T}$ & . & . & . $\mathrm{T}$ & $\mathrm{T}$. & . .. & · .. \\
\hline 6 & • & . & . & & & . . & $\mathrm{G}$ & . & .. & . & · & & & G & & . & 1 & $\mathrm{~T}$ & 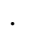 & . . & .. & . & . $\mathrm{T}$ & T $\mathrm{T}$ & $\mathrm{G}$ & . & $\cdot$ & . & . & $\cdot \mathrm{T}$ & . . & . . & · .. \\
\hline 7 & . & G & . & . & . & .. & G & . & $\cdot$. & . & . & ${ }^{\circ}$ & & G & . & . & $\mathrm{T}$ & $\mathrm{T}$ & $\cdot$ & . & $\cdot \cdot$ & . & - $\mathrm{T}$ & $\mathrm{T} \mathrm{T}$ & $\mathrm{G}$ & . & $\cdot$ & . & . & . $\mathrm{T}$ & . & .. & .. \\
\hline 8 & · & $\cdot$ & . & 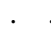 & $\cdot \quad$ & $\mathrm{G}$. & $\mathrm{G}$ & 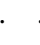 & . . & . & . & & . & G & . & . & T & $\mathrm{T}$ & . & . . & . . & . & $\cdot \mathrm{T}$ & $\mathrm{T} \mathrm{T}$ & $\mathrm{G}$ & . & $\cdot$ & . & . & $\cdot \mathrm{T}$ & . . & . . & .. \\
\hline 9 & . & $\cdot$ & . & . & . & .. & $\mathrm{G}$ & 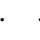 & . & . & . & . & . & $\mathrm{G}$ & . & . & $\mathrm{T}$ & $\mathrm{T}$ & . & . & - $\mathrm{G}$ & i & . $\mathrm{T}$ & $\mathrm{T} \mathrm{T}$ & $\mathrm{G}$ & . & . & . & . & . $\mathrm{T}$ & . . & - $\quad \mathrm{G}$ & G. \\
\hline 10 & · & $\cdot$ & & $\mathrm{G}$ & & $\cdot C$ & $\mathrm{SG}$ & A & . . & . & $\mathrm{C}$ & $\mathrm{T}$ & $\mathrm{T}$ & $\mathrm{G}$ & & . & & $\mathrm{T}$ & $\mathrm{C}$ & A $A$ & $\mathrm{~A}$. & $\mathrm{G}$ & $\mathrm{T} \mathrm{T}$ & $\mathrm{T} \mathrm{T}$ & . & . & $\cdot$ & & $\mathrm{C}$ & $\cdot \mathrm{T}$ & $\cdot \mathrm{C}$ & $\mathrm{G}$. & . \\
\hline 11 & . & $\cdot$ & & $\mathrm{G}$ & & $\cdot C$ & $\mathrm{~J} G$ & A 1 & $\Gamma$ & . & $\mathrm{C}$ & $\mathrm{T}$ & $\mathrm{T}$ & G & G & . & & $\mathrm{T}$ & $\mathrm{C}$ & A $A$ & $\mathrm{~A}$. & $\mathrm{G}$ & $\mathrm{T} \mathrm{T}$ & T $\mathrm{T}$ & . & . & . & . & $\mathrm{C}$ & $\cdot \mathrm{T}$ & $\cdot \mathrm{C}$ & $\mathrm{G} \cdot$ & $\cdot$ \\
\hline 12 & · & $\cdot$ & $\cdot$ & $\mathrm{G}$ & & $\cdot C$ & $\mathrm{~J} G$ & A & . & . & $\mathrm{C}$ & $\mathrm{T}$ & $\mathrm{T}$ & $\mathrm{G}$ & G & . & 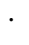 & $\mathrm{T}$ & $\mathrm{C}$ & A $A$ & $\mathrm{~A}$. & $\mathrm{G}$ & $\mathrm{T} \mathrm{T}$ & $\mathrm{T} \mathrm{T}$ & $\cdot$ & . & $\cdot$ & $\mathrm{T}$ & $\mathrm{C}$ & $\cdot \mathrm{T}$ & $\cdot \mathrm{C}$ & $\mathrm{G}$. & ·.. \\
\hline 13 & . & $\cdot$ & & $\mathrm{G}$ & A & $\cdot C$ & $\mathrm{G}$ & & . & I. & $\mathrm{C}$ & $\mathrm{T}$ & $\mathrm{T}$ & $\mathrm{G}$ & G & . & 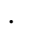 & $\mathrm{T}$ & $\mathrm{C}$ & A $A$ & $\mathrm{~A}$. & $\mathrm{G}$ & $\mathrm{T} \mathrm{T}$ & $\mathrm{T} \mathrm{T}$ & . & . & $\cdot$ & & $\mathrm{C}$ & . $\mathrm{T}$ & $\cdot \mathrm{C}$ & $\mathrm{G}$. & . \\
\hline 14 & . & $\cdot$ & $\cdot$ & G & A & $\cdot C$ & $\mathrm{~J} G$ & & . & . & $\mathrm{C}$ & $\mathrm{T}$ & $\mathrm{T}$ & G & G & . & & $\mathrm{T}$ & $\mathrm{C}$ & A & $\cdot \cdot$ & $\mathrm{G}$ & $\mathrm{T} \mathrm{T}$ & $\mathrm{T} \mathrm{T}$ & . & . & $\cdot$ & & $\mathrm{C}$ & $\cdot \mathrm{T}$ & $\cdot \mathrm{C}$ & $\mathrm{G} \cdot$ & . \\
\hline 15 & . & $\cdot$ & . & $\cdot$ & A & $\cdot C$ & $\mathrm{G}$ & & . & . & $\mathrm{C}$ & $\mathrm{T}$ & $\mathrm{T}$ & $\cdot$ & G & . & $\cdot$ & $\mathrm{T}$ & $\mathrm{C}$ & A & $\mathrm{A}$. & $\mathrm{G}$ & $\mathrm{T} \mathrm{T}$ & $\mathrm{T} \mathrm{T}$ & . & A & . & & $\mathrm{C}$ & . $\mathrm{T}$ & $\cdot \mathrm{C}$ & $\mathrm{G}$. & . \\
\hline 16 & & $\mathrm{G}$ & & G & & $\cdot C$ & $\mathrm{~B} G$ & & . & . & $\mathrm{C}$ & $\mathrm{T}$ & $\mathrm{T}$ & & G & . & & $\mathrm{T}$ & $\mathrm{C}$ & A $A$ & $\mathrm{~A}$. & $\mathrm{G}$ & $\mathrm{T} \mathrm{T}$ & T $\mathrm{T}$ & & A & $\cdot$ & & $\mathrm{C}$ & $\cdot \mathrm{T}$ & C & $\mathrm{G}$. & · \\
\hline 17 & . & $\cdot$ & $\cdot$ & $\mathrm{G}$ & A & $\cdot C$ & $\mathrm{~J} G$ & & . & . & $\mathrm{C}$ & $\mathrm{T}$ & $\mathrm{T}$ & $\cdot$ & G & . & & $\mathrm{T}$ & $\mathrm{C}$ & A & $\mathrm{A}$. & $\mathrm{G}$ & $\mathrm{T} \mathrm{T}$ & $\mathrm{T} \mathrm{T}$ & . & A & . & & $\mathrm{C}$ & $\cdot \mathrm{T}$ & $\cdot \mathrm{C}$ & $\mathrm{G}$. & \\
\hline
\end{tabular}

Nucleotide in bold results in amino acid substitution.

Table 3. Number of nucleotide substitutions in COI sequences among seven haplotypes in which the reproductive form was confirmed

\begin{tabular}{lrrrrrrr}
\hline Haplotype No. (Population name) & 10 & 12 & 14 & 15 & 16 & 6 & 7 \\
\hline 10 (AoRo) & - & & & & & & \\
12 (SaKa) & 1 & - & & & & \\
14 (ShHa, AoRo, WaMo) & 1 & 2 & - & & & \\
15 (WaKo, KaKa, NaKu, SaGe) & 3 & 4 & 4 & - & - & & \\
16 (WaMo, HiHi-1) & 3 & 4 & 4 & 2 & 1 & - \\
6 (OsHa, NaCh, HiHi-2) & 17 & 18 & 16 & 18 & 20 & 19 \\
7 (ShIz) & 18 & 19 & 17 & 19 & & \\
\hline
\end{tabular}

Haplotype numbers 10-16: thelytoky; 6, 7: arrhenotoky.

while the number of polymorphic sites among the four thelytokous haplotypes was 1-4 sites. In contrast, 16-20 substitution sites were found between the two reproductive forms.

The COI sequences used in phylogenetic analysis were $394 \mathrm{bp}$, which is common to all the sequences of $T$. tabaci and T. imagines. Although phylogenetic trees were estimated using the three methods of neighbor-joining (NJ), parsimony and maximum likelihood, their main stems showed the same pattern supported by high bootstrap values. We therefore show only the NJ tree in Fig. 1. The phylogenetic tree of the COI gene showed three distinct groups (Fig. 1). We call those groups
'Group A', 'Group B' and 'Group C'. Groups A and B included Haplotypes 1-9 and 10-17, respectively. Group C consisted of two haplotypes, AY196845 and AY196846. All arrhenotokous strains and male specimens were in Group A, while all thelytokous strains were in Group B. High bootstrap values supported that Groups A and B are a monophyletic group, while Group $\mathrm{C}$ shows no monophyly with them (Fig. 1).

The frequency distribution of the 17 haplotypes in 18 Japanese and eight overseas populations is shown in Table 4. Arrhenotoky consisting of two haplotypes, Haplotypes 6 and 7, was found in four Japanese populations. Overseas, males were found 


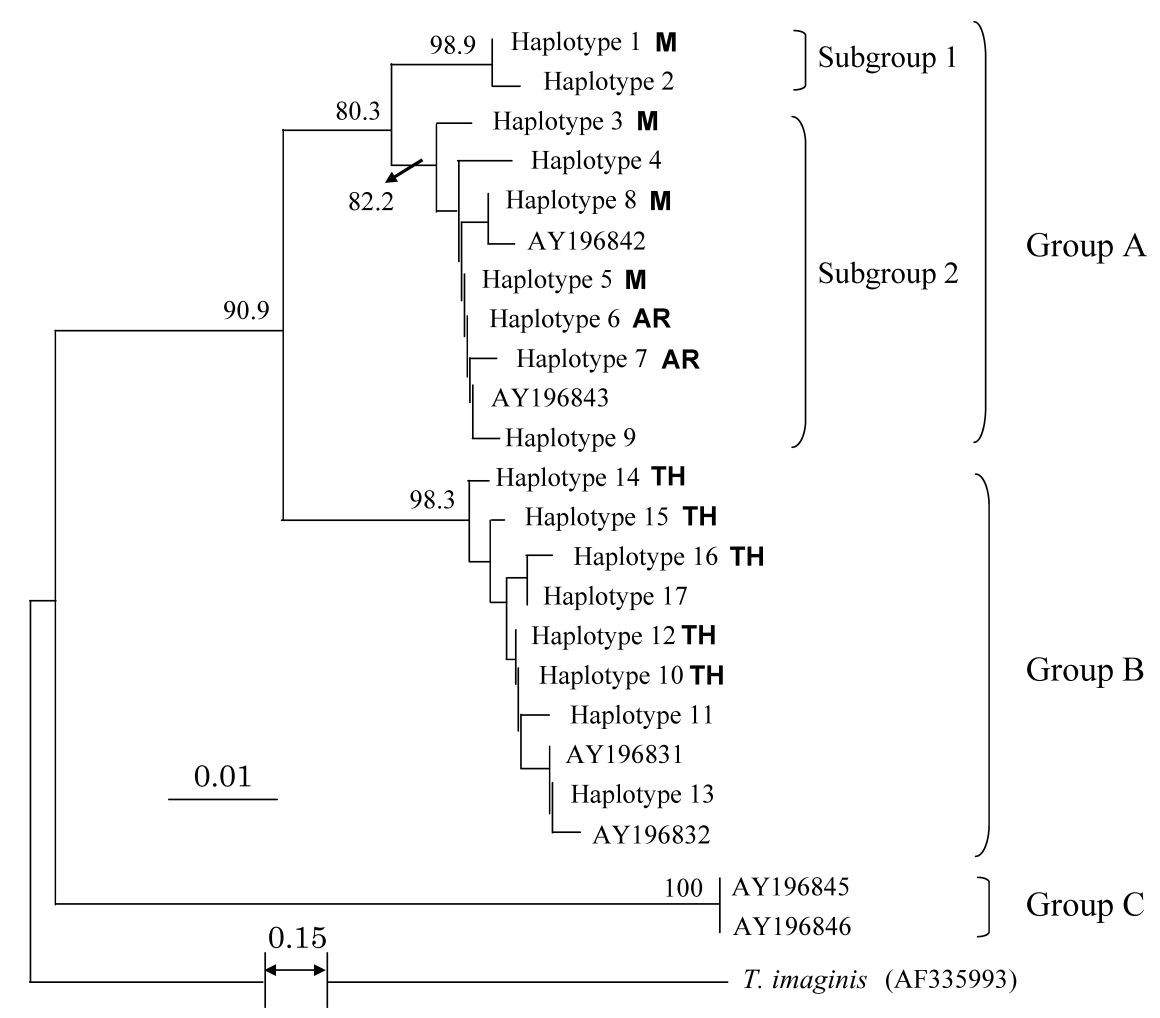

Fig. 1. Neighbor-joining tree based on 810 bases of the COI gene of $T$. tabaci. Bootstrap values $(1,000$ replicates $)>80 \%$ are shown above the branches. T. imaginis (AF335993) served as an outgroup. The accession numbers in Groups A, B and C show the sequence data of T. tabaci obtained from DNA databases. TH, AR and M show that the thelytokous strain, arrhenotokous strain and males were contained in the samples, respectively.

in only two countries, the Netherlands and Israel. The geographic distribution of Haplotypes 1-9 in Group A did not overlap among three countries except for Haplotype 8. Haplotypes 1 and 2 formed a subgroup supported by a high bootstrap value (Subgroup 1 in Fig. 1). Five thelytokous haplotypes (Haplotypes 10, 12, 14, 15 and 16) were found in Japanese populations (Table 4). Haplotypes 10, 15 and 16 were found both overseas and in Japan. Haplotype 16 was found in three overseas populations, FRA, KEN and PER, and two Japanese populations, WaMo and HiHi-1. Haplotype 15, found in ChTa, WaMo, $\mathrm{KaKa}, \mathrm{SaGe}$ and $\mathrm{NaKu}$, was also found in ISR-1. In Japan, Haplotype 14 was detected over a geographically wide range.

\section{DISCUSSION}

A comparison of the nucleotide sequences of the mitochondrial COI gene revealed that Japanese arrhenotokous and thelytokous $T$. tabaci have at least two and five haplotypes, respectively. The nu- cleotide sequence apparently differed between the two reproductive forms, while high homology was observed in each reproductive form. Moreover, phylogenetic analysis, including the overseas strain, showed that the samples used in this study were divided into two separate groups. Japanese arrhenotokous strains ( $\mathrm{ShIz}, \mathrm{OsHa}, \mathrm{NaCh}$, and HiHi2 ) and all male samples, with a few females from the Netherlands (NDL-1 and -2) and Israel (ISR-1 and -2), formed an independent clade (Group A in Fig. 1). Since we can regard males as arrhenotokous, we assumed that this group was arrhenotokous. The two subgroups in Fig. 1 may indicate a difference in their geographic origin. In contrast, all thelytokous strains were included in Group B, suggesting that Group B is thelytokous. The divergence of Groups A and B was supported by a high bootstrap value (Fig. 1).

Brunner et al. (2004), after conducting molecular phylogenetic analysis, proposed three distinct major lineages (T, L1 and L2) in T. tabaci. They suggested that $\mathrm{T}$ is the tobacco-associated lineage, 
Table 4. Frequency distribution of 17 COI haplotypes in 18 Japanese and eight overseas populations

\begin{tabular}{|c|c|c|c|c|c|c|c|c|c|c|c|c|c|c|c|c|c|}
\hline \multirow{2}{*}{$\begin{array}{l}\text { Population } \\
\text { name }\end{array}$} & \multicolumn{17}{|c|}{ Haplotypes } \\
\hline & 1 & 2 & 3 & 4 & 5 & 6 & 7 & 8 & 9 & 10 & 11 & 12 & 13 & 14 & 15 & 16 & 17 \\
\hline $\mathrm{HoNa}$ & - & - & - & - & - & - & - & - & - & - & - & - & - & 5 & - & - & - \\
\hline AoRo & - & - & - & - & - & - & - & - & - & 5 & - & - & - & 5 & - & - & - \\
\hline IwMo & - & - & - & - & - & - & - & - & - & - & - & - & - & 5 & - & - & - \\
\hline ChTa & - & - & - & - & - & - & - & - & - & - & - & 1 & - & - & 1 & - & - \\
\hline $\mathrm{ShHa}$ & - & - & - & - & - & - & - & - & - & - & - & - & - & 5 & - & - & - \\
\hline $\mathrm{NaCh}$ & - & - & - & - & - & 2 & - & - & - & - & - & - & - & - & - & - & - \\
\hline OsHa & - & - & - & - & - & 2 & - & - & - & - & - & - & - & - & - & - & - \\
\hline WaMo & - & - & - & - & - & - & - & - & - & - & - & - & - & - & 1 & 2 & - \\
\hline WaKo & - & - & - & - & - & - & - & - & - & - & - & - & - & 2 & - & - & - \\
\hline HiHi-1 & - & - & - & - & - & - & - & - & - & - & - & - & - & - & - & 5 & - \\
\hline $\mathrm{HiHi}-2$ & - & - & - & - & - & 2 & - & - & - & - & - & - & - & - & - & - & - \\
\hline ShIz & - & - & - & - & - & - & 2 & - & - & - & - & - & - & - & - & - & - \\
\hline $\mathrm{KaKa}$ & - & - & - & - & - & - & - & - & - & - & - & - & - & 1 & 5 & - & - \\
\hline $\mathrm{SaKa}$ & - & - & - & - & - & - & - & - & - & - & - & 1 & - & - & - & - & - \\
\hline $\mathrm{SaGe}$ & - & - & - & - & - & - & - & - & - & - & - & - & - & - & 1 & - & - \\
\hline $\mathrm{NaKu}$ & - & - & - & - & - & - & - & - & - & - & - & - & - & - & 5 & - & - \\
\hline $\mathrm{KaKu}$ & - & - & - & - & - & - & - & - & - & - & - & - & - & 5 & - & - & - \\
\hline $\mathrm{OkNa}$ & - & - & - & - & - & - & - & - & - & - & - & - & - & 5 & - & - & - \\
\hline KOR & - & - & - & - & - & - & - & - & - & 5 & - & - & - & - & - & - & - \\
\hline NLD-1 & - & - & - & - & 1 & - & - & 1 & 1 & - & - & - & 1 & - & - & - & - \\
\hline NLD-2 & - & - & 1 & 2 & 3 & - & - & 3 & 1 & - & - & - & - & - & - & - & - \\
\hline FRA & - & - & - & - & - & - & - & - & - & - & 3 & - & - & - & - & 5 & 4 \\
\hline ISR-1 & 5 & - & - & - & - & - & - & 3 & - & - & - & - & - & - & 1 & - & - \\
\hline ISR-2 & 1 & 2 & - & - & - & - & - & - & - & - & - & - & - & - & - & - & 1 \\
\hline KEN & - & - & - & - & - & - & - & - & - & - & - & - & - & - & - & 4 & - \\
\hline PER & - & - & - & - & - & - & - & - & - & - & - & - & - & - & - & 2 & - \\
\hline
\end{tabular}

and L1 and L2 are the leek-associated lineages. Two haplotypes, AY196845 and AY196846, belong to the tobacco type (T). Similarly, AY196842 and AY196843 are members of L1, and AY196831 and AY196832 are L2. These suggest that Groups A, B and $\mathrm{C}$ correspond to lineages L1, L2 and T, respectively. In this study, we found no samples belonging to Group C. This is attributable to the fact that no sample was collected from host plants of the tobacco type as described in Zawirska (1976). It has been pointed out that the tobacco type is arrhenotokous, and the leek type consists of both arrhenotoky and thelytoky (Zawirska, 1976). Thus, Brunner et al. (2004) and our study both suggest that an ancient arrhenotokous strain differentiated into two types, the tobacco $(\mathrm{T})$ and leek $(\mathrm{L})$ types, and then a thelytokous type (L2) was derived from the arrhenotokous leek type (L1). Chatzivassiliou et al. (2002) revealed that arrhenotokous populations collected from tobacco transmitted TSWV effi- ciently (up to $48.5 \%$ transmission) and those from leek were poor transmitters (up to $3.1 \%$ ), whereas no transmission was obtained with thelytokous populations from leeks. These facts show that the ability to transmit TSWV is closely linked to host preference and may also support the above-mentioned hypothesis in relation to the differentiation process of the three strains. Brunner et al. (2004) proposed that the relationship between $\mathrm{T}$ and the others corresponds to that of sibling species, and the two leek haplotypes (L1 and L2) correspond to typical host-race estimates according to their Fst value. In our study, the NJ tree with high bootstrap values suggested that Groups A and B are a monophyletic group, while Group $\mathrm{C}$ shows no monophyly with them. This result supports the phylogenetic relationship proposed by Brunner et al. (2004). Murai (data unpublished) observed that, although arrhenotokous males attempted to copulate with thelytokous females, the males were rejected, 
suggesting the existence of reproductive isolation. This phenomenon was also observed between two reproductive forms of $T$. nigropilosus and suggested that they are a separate species (Nakao and Yabu, 1998). To discuss the taxonomical relationship between two reproductive forms of $T$. tabaci, it is necessary to investigate their reproductive isolation in detail.

Japanese thelytokous types consist of five haplotypes (Table 2). Haplotypes 12 and 14 were found only in Japan (Table 4). It was speculated that Haplotype 14 is the most common type distributed in Japan, since it was the most frequently found across Japan and has never been collected from problematic populations. Haplotypes 10, 15 and 16 were found in both Japanese and overseas populations (Table 3). Haplotype 10 was found also in Korea. Murai and Toda (2002) revealed that Haplotype 10 thrips collected in AoRo had a paler body color and smaller body size than that of Haplotype 14 collected in the same locality. Although there is a possibility that this haplotype originated overseas, we believe that this is not problematic type, since we have found no marked traits in insecticide resistance and host range in this haplotype. Haplotype 16 is also distributed in three overseas countries (France, Kenya and Peru), and Haplotype 15 was detected in Israeli samples. In this study, Haplotypes 15 and 16 were identified from persimmon, asparagus, Satsuma mandarin and florist crop populations in Wakayama, Kagawa, Saga and Chiba Prefectures, respectively (Table 1). They are problematic populations because of the extent of damage and/or decreased susceptibility to some insecticides (Morishita and Oue, 2001; Oida and Mihira, 2001; Matsumoto, 2004; Zen, personal communication). The expansion of damage on the abovementioned crops and the decrease of insecticide susceptibility were all first reported in the late 1990 s to early 2000s in Japan. Insecticide resistance in T. tabaci began to be reported in the late 1980s overseas (Cranshaw et al., 1989), and has recently become a serious problem (Shelton et al., 2003; Allen et al., 2005). These facts may suggest that different types of thelytokous strains invaded Japan during that period and caused agricultural problems; however, we need to analyze more overseas samples to clarify the relationship between Japanese and overseas populations.

In this study, we found a variety of mitochon- drial COI haplotypes in T. tabaci. All populations which have been causing serious agricultural problems are thelytokous so far, suggesting that the problematic traits are maternally inherited. If there is genetic variation in such traits, we may develop a genetic marker which closely links to problematic traits using COI and/or other haplotypes. Thus, further genetic analysis may contribute to the development of an efficient control method of T. tabaci.

\section{ACKNOWLEDGEMENTS}

We are grateful to the following people for collecting Japanese thrips samples: T. Arai, H. Hayashi, S. Hayashikawa, O. Kanehira, S. Masui, E. Matsumoto, T. Mihira, M. Morishita, Y. Sakagami, M. Shibao and S. Zen. We are also grateful to Drs. G.-S. Lee (National Institute of Agricultural Science and Technology, Korea) and G. Vierbergen (Plantenziektenkundige Dienst, the Netherlands) for collecting and identifying the Korean and other five overseas samples, respectively. We also thank Dr. S. Komazaki of the National Institute of Fruit Tree Science for valuable advice on this study.

\section{REFERENCES}

Allen, J. K. M., C. D. Scott-Dupree, J. H. Tolman and C. R. Harris (2005) Resistance of Thrips tabaci to pyrethroid and organophosphorus insecticides in Ontario, Canada. Pest Manag. Sci. 61: 809-815.

Brunner, P. C., E. K. Chatzivassiliou, N. I. Katis and J. E. Frey (2004) Host-associated genetic differentiation in Thrips tabaci (Insecta; Thysanoptera), as determined from mtDNA sequence data. Heredity 93: 364-370.

Chatzivassiliou, E. K., D. Peters and N. I. Katis (2002) The efficiency by which Thrips tabaci populations transmit Tomato spotted wilt virus depends on their host preference and reproductive strategy. Phytopathology 92: 603-609.

Cranshaw, W. S. (1989) Control of organophosphate-resistant onion thrips. Insecticide Acaricide Test 14: 128.

Doi, M., S. Zen, M. Okuda, H. Nakamura, K. Kato and K. Hanada (2003) Leaf necrosis disease of lisianthus (Eustoma grandiflorum) caused by Iris yellow spot virus. Jpn. J. Phytopathol. 69: 181-188 (in Japanese with English summary).

Felsenstein, J. (2005) PHYLIP: Phylogeny inference package, version 3.6. Department of Genome Sciences, University of Washington, Seattle.

Fujikawa, K. and T. Muta (2003) Occurrence and chemical susceptibility of onion thrips (Thrips tabaci Lindeman) in greenhouses of Satuma mandarin in Kagoshima Prefecture. Plant Prot. 57: 61-64 (in Japanese).

Jenser, G. and Á. Szénási (2004) Review of the biology and vector capability of Thrips tabaci Lindeman (Thysanoptera: Thripidae). Acta Phytopathol. Entomol. Hung. 39: 137-155.

Jenser, G., Á. Szénási, O. Törjék, G. Gyulai, E. Kiss, L. Heszky and J. Fail (2001) Molecular polymorphism between population of Thrips tabaci Lindeman 
(Thysanoptera: Thripidae) propagating on tobacco and onion. Acta Phytopathol. Entomol. Hung. 36: 365-368.

Kimura, M. (1980) A simple model for estimating evolutionary rates of base substitutions through comparative studies of nucleotide sequences. J. Mol. Evol. 16: 111-120.

Matsumoto, E. (2004) Occurrence and management of Thrips tabaci on green asparagus. Japan Agricultural Technology 48(8): 34-38 (in Japanese).

Morishita, M. and H. Oue (2001) Damage of persimmon fruit by onion thrips, Thrips tabaci (Lindeman) (Thysanoptera: Thripidae), and its chemical control. Proc. Kansai Plant Prot. Soc. 43: 43-44 (in Japanese with English summary).

Murai, T. (1990) Parthenogenetic reproduction in Thrips tabaci and Frankliniella intonsa (Insecta: Thysanoptera). In Advances in Invertebrate Reproduction. Vol. 5 (M. Hoshi and O. Yamashita eds.). Elsevier Science, Amsterdam, pp. 357-362.

Murai, T. (2004) Current status of the onion thrips, Thrips tabaci, as a pest thrips in Japan. Agrochemicals Japan 84: 7-10.

Murai, T. and A. J. M. Loomans (2001) Evaluation of an improved method for mass-rearing of thrips and a thrips parasitoid. Entomol. Exp. Appl. 101: 281-289.

Murai, T. and S. Toda (2002) Variation of Thrips tabaci in colour and size. In Thrips and Tospoviruses: Proceedings of the 7th International Symposium on Thysanoptera (R. Marullo and L. A. Mound eds.). Australian National Insect Collection, Canberra, pp. 377-378.

Nakao, S. and S. Yabu (1998) Ethological and chemical discrimination between thelytokous and arrhenotokous Thrips nigropilosus Uzel, with discussion of taxonomy. Jpn. J. Appl. Entomol. Zool. 42: 77-83 (in Japanese with English summary).

Navajas, M., D. Fournier, J. Lagnel, J. Gutierrez and P. Boursot (1996) Mitochondrial COI sequences in mites: evidence for variations in base composition. Insect Mol. Biol. 5: 281-285.

Nishimori, T., K. Imai, M. Yamada, N. Miki and S. Kobayashi
(2003) Insecticide susceptibility of onion thrips, Thrips tabaci Lindeman, collected in vegetable field and mass rearing method. Plant Prot. 57: 56-60 (in Japanese).

Oida, H. and T. Mihira (2001) Damage from Thrips tabaci on florist crops and its management. Agriculturist and Horticulturist 56: 178-181 (in Japanese).

Shao, R. and S. C. Barker (2003) The highly rearranged mitochondrial genome of the plague thrips, Thrips imaginis (Insecta: Thysanoptera): Convergence of two novel gene boundaries and an extraordinary arrangement of rRNA genes. Mol. Biol. Evol. 20: 362-370.

Shelton, A. M., B. A. Nault, J. Plate and J.-Z. Zhao (2003) Regional and temporal variation in susceptibility to lambda-cyhalothrin in onion thrips, Thrips tabaci (Thysanoptera: Thripidae), in onion fields in New York. J. Econ. Entomol. 96: 1843-1848.

Thompson, J. D., D. G. Higgins and T. J. Gibson (1994) CLUSTAL W: Improving the sensitivity of progressive multiple sequence alignment through sequence weighting, positions-specific gap penalties and weight matrix choice. Nucleic Acids Res. 22: 4673-4680.

Toda, S. and S. Komazaki (2002) Identification of thrips species (Thysanoptera: Thripidae) on Japanese fruit trees by polymerase chain reaction and restriction fragment length polymorphism of the ribosomal ITS2 region. Bull. Entomol. Res. 92: 359-363.

Tsuchiya, M. (2001) Occurrence of blemished fruits caused by Thrips tabaci on greenhouse Satsuma mandarins in Shizuoka Prefecture. Annu. Rep. Kanto-Tosan Plant Prot. Soc. 48: 153-155 (in Japanese with English summary).

Zawirska, I. (1976) Untersuchungen über zwei biologische Typen von Thrips tabaci Lind. (Thysanoptera, Thripidae) in der VR Polen. Arch. Phytopathol. Pflanzenschutz 12: 411-422.

Zhang, D.-X. and G. M. Hewitt (1996) Assessment of the universality and utility of a set of conserved mitochondrial COI primers in insects. Insect Mol. Biol. 6: 143150. 